\title{
VOLATILIZATION OF METALLIC COMPOUNDS FROM SOLUTIONS IN PERCHLORIC OR SULFURIC ACID
}

\author{
By James I. Hoffman and G. E. F. Lundell
}

ABSTRACT

Distillation from perchloric or sulfuric acid solutions, during the gradual addition of hydrochloric or hydrobromic acid to the hot solution $\left(200^{\circ}\right.$ to $\left.220^{\circ} \mathrm{C}\right)$, was undertaken to obtain information on the volatility under these conditions of elements that might be encountered in chemical analysis. It was found that, if proper conditions are established, antimony, arsenic, chromium, germanium, osmium, rhenium, ruthenium, and tin can be quantitatively distilled from perchloric acid, and germanium, arsenic, selenium, tin, antimony, and rhenium from sulfuric acid solutions. Certain others, as bismuth, boron, gold, molybdenum, tellurium, and thallium, may be lost in part from either perchloric or sulfuric acid solutions. From the information obtained, certain precautions against unintentional losses are evident, and certain possible separations of elements are indicated.

I. Introduction.

CONTENTS

II. Experimental Work

III. Discussion of results

1. Separation of chromium _.

2. Separations of other elements

3. Losses that may cause errors in analytical procedures _....... 469

\section{INTRODUCTION}

Volatilization as chromyl chloride, $\mathrm{CrO}_{2} \mathrm{Cl}_{2}$, has been employed by Smith $^{1}$ as a means of eliminating chromium in determinations of manganese, nickel, and vanadium, in steels containing high percentages of chromium. Certain other chlorides, notably those of antimony, arsenic, germanium, mercury, selenium, and tin, are likewise known to be volatile at or below $200^{\circ} \mathrm{C}$, the temperature at which chromyl chloride is distilled. The present work was undertaken to obtain further information on the elements mentioned, as well as on other elements that might be encountered in chemical analysis. In this, two distinct purposes were kept in mind. The first was to find possible separations of elements that can not be separated by distilling at temperatures below $200^{\circ} \mathrm{C}$. The second was to obtain information on elements that might be lost unintentionally when solutions are evaporated with perchloric or sulfuric acid in such operations as dehydration of silicic acid or expulsion of fluorides. Distillations with hydrobromic acid were included because they are sometimes used, and because certain bromides are even more volatile than the corresponding chlorides.

1 Fred Wilson Smith, Ind. Eng. Chem., Anal. Ed. 10, 360 (1938); and Chemists U. S. Steel Corporation, Sampling and Analysis of Carbon and Alioy Steels, p. 70, 77, 132, and 157, (Reinhold Publishing Co., New York, N. Y., 1938 ed.) 


\section{EXPERIMENTAL WORK}

In Smith's procedure the steel is dissolved in an Erlenmeyer flask in a mixture of hydrochloric and perchloric acids, and the chromium is oxidized to the sexivalent state by heating the solution until copious fumes of perchloric acid are evolved. The chromium is then volatilized as chromyl chloride by adding successive small portions of sodium

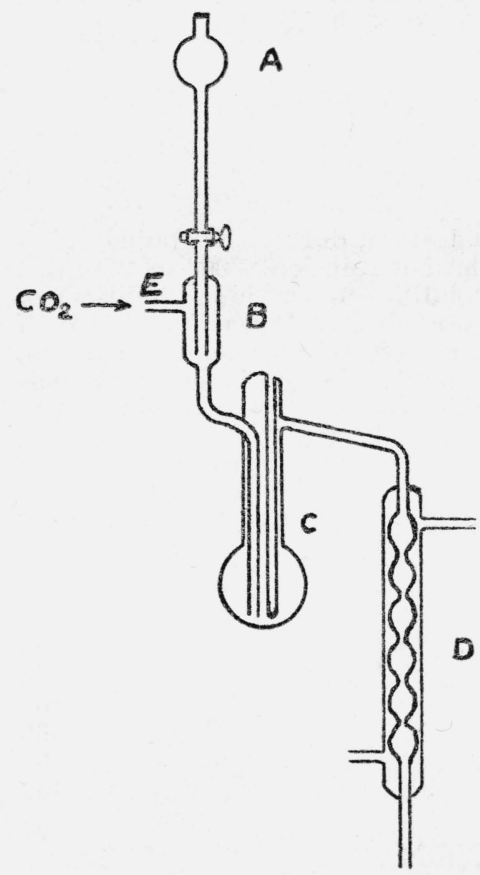

FIGURE 1.-Distilling apparatus. chloride or hydrochloric acid to the hot solution. At least 99 percent of the chromium is easily eliminated in this way.

In the present work, an Erlenmeyer flask was not suitable because it was desired to test the volatile portion as well as the residual solution in the flask. The distilling apparatus devised by J. A. Scherrer ${ }^{2}$ is well suited for this purpose and has the added advantages that the hydrochloric or hydrobromic acid can be admitted at any desired rate, that the temperature of the solution can be observed at all times, and that rubber stoppers, which might cause serious explosions, are avoided. ${ }^{3}$ The apparatus is illustrated in figure 1. The flask has a capacity of $200 \mathrm{ml}$, and the distance between the bottom of the flask and the outlet tube leading to the condenser is about $15 \mathrm{~cm}$.

The following six types of distillations were investigated: (1) Distillation with perchloric and hydrochloric acids; (2) distillation with perchloric and hydrobromic acids; (3) distillation with perchloric, phosphoric, and hydrochloric acids; (4) distillation with perchloric, phosphoric, and hydrobromic acids; (5) distillation with sulfuric and hydrochloric acids; and (6) distillation with sulfuric and hydrobromic acids.

(1) Procedure for distillation with perchloric and hydrochloric acids.To facilitate rapid heating of the contents of the flask, and at the same time to protect the upper portion of the flask from excessive heating, the bottom of the distilling flask was placed over a $4-\mathrm{cm}$ hole in a wire gauze with asbestos center. The distillate was collected in a beaker containing $100 \mathrm{ml}$ of cold distilled water, so placed that the tip of the condenser $D$ was slightly immersed. From 25 to $100 \mathrm{mg}$ of the element under test, usually in the form of a solution of its chloride or perchlorate, was introduced into the distilling flask through $A$; then

2 J. Research NBS 16, 255 (1936) RP871; 21, 95 (1938) RP1116.

3 It should be remembered that at the temperatures used in this work perchloric acid is a powerful oxidizing agent and may therefore react with explosive violence if it comes in contact with certain reducing substances, such as organic matter. 
TABLE 1.-Results obtained in distillations at 200 to $220^{\circ} \mathrm{C}$

\begin{tabular}{|c|c|c|c|c|c|c|}
\hline \multirow[b]{2}{*}{ Element 1} & \multicolumn{6}{|c|}{ Approximate percentage volatilized from 20 to 100 -mg portions by distillation with- } \\
\hline & $\mid \begin{array}{c}\mathrm{HCl}-\mathrm{HClO} \\
(\text { Procedure }\end{array}$ & $\underset{\text { (Procedure_2) }}{\mathrm{H} \mathrm{Br}-\mathrm{HClO}_{4}}$ & $\begin{array}{c}\mathrm{HCl}-\mathrm{H}_{3} \mathrm{PO}_{4} \\
\text { - } \mathrm{HClO}_{4} \\
\text { (Procedure 3) }\end{array}$ & $\mid \begin{array}{c}\mathrm{HBr}-\mathrm{H}_{3} \mathrm{PO}_{4} \\
-\mathrm{HClO}_{4} \\
(\text { Procedure }\end{array}$ & $\mid \begin{array}{c}\mathrm{HCl}-\mathrm{H}_{2} \mathrm{SO}_{4} \\
\text { (Procedure 5) }\end{array}$ & $\underset{\text { (Procedure } 6 \text { ) }}{\mathrm{HBr}-\mathrm{H}_{2} \mathrm{SO}}$ \\
\hline 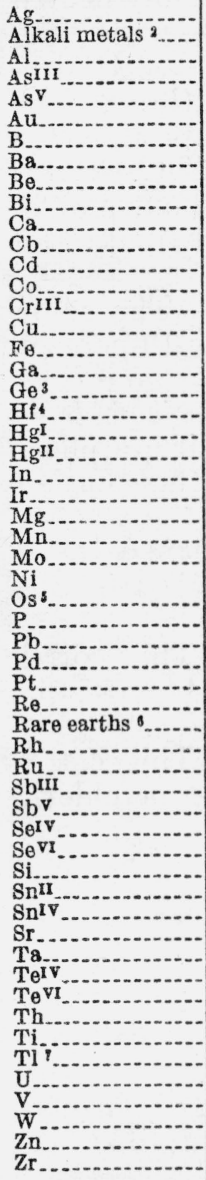 & $\begin{array}{c}0 \\
0 \\
0 \\
30 \\
5 \\
1 \\
20 \\
0 \\
0 \\
0.1 \\
0 \\
0 \\
0 \\
0 \\
99.7 \\
0 \\
0 \\
0 \\
50 \\
0 \\
75 \\
75 \\
0 \\
0 \\
0 \\
0.1 \\
3 \\
0 \\
100 \\
1 \\
0 \\
0 \\
0 \\
100 \\
0 \\
0 \\
99.5 \\
2 \\
2 \\
4 \\
4 \\
0 \\
99.8 \\
100 \\
0 \\
0 \\
0.5 \\
0.1 \\
0 \\
0 \\
1 \\
0 \\
0.5 \\
0 \\
0 \\
0 \\
\\
\\
\\
\\
\\
\\
\\
\\
\\
\\
\end{array}$ & $\begin{array}{c}0 \\
0 \\
0 \\
100 \\
100 \\
0.5 \\
20 \\
0 \\
0 \\
1 \\
0 \\
0 \\
0 \\
0 \\
40 \\
0 \\
0 \\
0 \\
70 \\
0 \\
75 \\
75 \\
0 \\
0 \\
0 \\
0.02 \\
12 \\
0 \\
100 \\
1 \\
0 \\
0 \\
0 \\
100 \\
0 \\
0 \\
100 \\
99.8 \\
99.8 \\
2 \text { to } \\
5 \\
0 \\
100 \\
100 \\
0 \\
0 \\
0.5 \\
0.5 \\
0 \\
0 \\
1 \\
0 \\
2 \\
0 \\
0 \\
0 \\
\end{array}$ & $\begin{array}{c}0 \\
0 \\
0 \\
30 \\
5 \\
0.5 \\
10 \\
0 \\
0 \\
0 \\
0 \\
0 \\
0 \\
0 \\
99.8 \\
0 \\
0 \\
0 \\
10 \\
0 \\
75 \\
75 \\
0 \\
0 \\
0 \\
0.02 \\
0 \\
0 \\
100 \\
1 \\
0 \\
0 \\
0 \\
80 \\
0 \\
0 \\
100 \\
2 \\
0 \\
2 \text { to } 5 \\
5 \\
0 \\
0 \\
0 \\
0 \\
0 \\
0.1 \\
0.1 \\
0 \\
0 \\
1 \\
0 \\
0 \\
0 \\
0 \\
0 \\
\end{array}$ & $\begin{array}{c}0 \\
0 \\
0 \\
100 \\
100 \\
0.5 \\
10 \\
0 \\
0 \\
1 \\
0 \\
0 \\
0 \\
0 \\
40 \\
0 \\
0 \\
0 \\
90 \\
0 \\
75 \\
75 \\
0 \\
0 \\
0 \\
0.02 \\
0 \\
0 \\
100 \\
1 \\
0 \\
0 \\
0 \\
100 \\
0 \\
0 \\
100 \\
99.8 \\
99.8 \\
2 \text { to } \\
5 \\
0 \\
99.8 \\
100 \\
0 \\
0 \\
0.5 \\
1 \\
0 \\
0 \\
1 \\
0 \\
0 \\
0 \\
0 \\
0 \\
\end{array}$ & $\begin{array}{c}0 \\
0 \\
0 \\
100 \\
5 \\
0.5 \\
50 \\
0 \\
0 \\
0 \\
0 \\
0 \\
0 \\
0 \\
0 \\
0 \\
0 \\
0 \\
90 \\
0 \\
75 \\
75 \\
0 \\
0 \\
0 \\
0.02 \\
5 \\
0 \\
0 \\
1 \\
0 \\
0 \\
0 \\
90 \\
0 \\
0 \\
0 \\
33 \\
2 \\
30 \\
20 \\
0 \\
1 \\
30 \\
0 \\
0 \\
0.1 \\
0.1 \\
0 \\
0 \\
0.1 \\
0 \\
0 \\
0 \\
0 \\
0 \\
\\
\\
\\
\\
\\
\\
\\
\\
\\
\\
\\
\\
\\
\end{array}$ & $\begin{array}{c}0 \\
0 \\
0 \\
100 \\
100 \\
0.5 \\
10 \\
0 \\
0 \\
1 \\
0 \\
0 \\
0 \\
0 \\
0 \\
0 \\
0 \\
0 \\
95 \\
0 \\
00 \\
90 \\
0 \\
0 \\
0 \\
0.02 \\
4 \\
0 \\
0 \\
1 \\
0 \\
0 \\
0 \\
100 \\
0 \\
0 \\
0 \\
99.8 \\
98 \\
100 \\
100 \\
0 \\
100 \\
100 \\
0 \\
0 \\
10 \\
10 \\
0 \\
0 \\
1 \\
0 \\
0 \\
0 \\
0 \\
0 \\
\\
\\
\\
\\
\\
\\
\\
\end{array}$ \\
\hline
\end{tabular}

1 Valences given in this column are those of the elements in the distilling flask at the beginning of the distillation.

This includes lithium, sodium, potassium, rubidium, and cesium.

3 The results given here are those obtained by heating the sulfuric or perchloric acid solutions in the distilling flask to $200^{\circ} \mathrm{C}$ before admitting the hydrochloric or hydrobromic acid. During the heating, GeO, separated. By adding hydrochloric or bydrobromic acid to the solution before heating, separation of $\mathrm{GeO}_{3}$ did not occur, and the germanium readily passed in to the distillate.

Since pure hafnium was not a vailable, this test was made by decomposing $2 \mathrm{~g}$ of cyrtolite and distilling as indicated. Spectrochemical tests showed that hafnium was one of the constituents of the mineral. It is supposed to contain 3 to 5 percent of $\mathrm{HfO}_{2}$.

At 200 to $220^{\circ} \mathrm{C}$ no osmium was volatilized from the solutions containing sulfuric acid; however, at 270 to $300^{\circ} \mathrm{C}$ the osmium was completely volatilized.

- This includes scandium, yttrium, and lanthanum in addition to the rare earths, cerium, praseodymium, neodymium, samarium, europium, gadolinium, terbium, dysprosium, holmium, erbium, thulium, ytterbium, and lutecium. A mixture in which all these elements were known to be present was used in this distillation.

In distilling from sulfuric acid, a few tests were made in which hydrochloric acid containing sulfurous acid was added to the hot sulfuric acid solution in the distilling flask. This was done to keep the thallium in the univalent state. No thallium was found in the distillates, whereas a little (about $1 \mathrm{mg}$ ) was always found if the thallium wos first oxidized. 
$15 \mathrm{ml}$ of 60-percent perchloric acid was added, and the stopcock was closed. A moderate stream of dry carbon dioxide was admitted through tube $E$ and bubbled through the solution in the distilling flask. This swept the vapors from the flask into the condenser and prevented bumping by keeping the solution agitated. After the stream of gas was started, the contents of the flask were rapidly heated to $200^{\circ} \mathrm{C}$ with a Tirrill burner. The temperature was observed with a thermometer placed in the thermometer well of the flask. Hydrochloric acid, sp gr 1.18, from bulb $A$ was now introduced through the inlet tube beneath the surface of the hot solution in the flask at such a rate that the temperature remained between $200^{\circ}$ and $220^{\circ} \mathrm{C}$. After $15 \mathrm{ml}$ of hydrochloric acid had been admitted, during the course of 20 to 30 minutes, the distillation was stopped, and the distillate and residual solution in the flask were examined.

(2) Distillation with perchloric and hydrobromic acids.-The same procedure was used as in (1), except hydrobromic acid (the 40-percent reagent) was substituted for hydrochloric acid.

(3) Distillation with perchloric, phosphoric, and hydrochloric acids.The same procedure was used as in (1), except $5 \mathrm{ml}$ of sirupy phosphoric acid was added to the contents of the flask before the solution was heated and the hydrochloric acid admitted.

(4) Distillation with perchloric, phosphoric, and hydrobromic acids.The same procedure was used as in (3), except hydrobromic acid was substituted for hydrochloric acid.

(5) Distillation with sulfuric and hydrochloric acids.-This corresponded exactly with (1), except sulfuric acid (sp gr 1.84) was substituted for perchloric acid.

(6) Distillation with sulfuric and hydrobromic acids.-This corresponded with (2), except sulfuric acid was substituted for perchloric acid.

The results of the tests are given in table 1.

\section{DISCUSSION OF RESULTS}

\section{SEPARATION OF CHROMIUM}

This work confirms the statement of Smith ${ }^{4}$ that by distilling with perchloric and hydrochloric acids chromium can be satisfactorily separated from manganese in analyses of steels containing high percentages of chromium. The amount of manganese volatilized is entirely negligible in any ordinary analysis. ${ }^{5}$

\section{SEPARATIONS OF OTHER ELEMENTS}

Complete distillation can probably be obtained in a reasonable time with those elements in table 1 that have passed into the distillate to the extent of 50 percent or more, but such a procedure would most likely be impractical in the case of boron.

The table shows that arsenic, antimony, and tin can be volatilized, and additional work indicates that a practical method can probably be

\footnotetext{
Ind. Eng. Chem., Anal. Ed. 10, 360 (1938).

For example, in determinations of manganese in 1-g samples of 18 chromium-8 nickel steel (NBS Standard Sample 101) after volatilizing the chromium as chromyl chloride, 0.559 and 0.553 percent, respectively, were obtained as compared with the certificate value, 0.555 percent.
} 
developed for separating small percentages of these from as much as 5 $\mathrm{g}$ of lead, by distilling with hydrobromic and perchloric acids at $200^{\circ}$ to $220^{\circ} \mathrm{C}$.

If the reactions of the neighboring elements in the periodic system can be used as a criterion, it should be possible to volatilize the element masurium by distilling with perchloric and hydrochloric acids.

Selenium can be separated from many other elements by distillation with hydrobromic and sulfuric acids ${ }^{6}$ (procedure 6).

Rhenium can be separated from molybdenum by distilling from a mixture of perchloric and phosphoric acids to which hydrobromic acid is slowly added (procedure 4). In a distillation involving $0.25 \mathrm{~g}$ of molybdenum, the presence of molybdenum was detected in the distillate, but the amount was less than $0.05 \mathrm{mg}{ }^{7}$

Since preliminary experiments indicated that molybdenum can be volatilized in part by distilling at $200^{\circ}$ to $220^{\circ} \mathrm{C}$ with sulfuric and hydrochloric acids or with sulfuric and hydrobromic acids, additional distillations were made at temperatures as high as $300^{\circ} \mathrm{C}$ in an attempt to get complete separation of molybdenum. These distillations were continued for at least one hour, and as much as $50 \mathrm{ml}$ of the halogen acids was used. Even with these more drastic treatments, volatilization was far from complete. The use of dry gaseous hydrogen chloride with either perchloric or sulfuric acid likewise failed to effect sufficient volatilization to offer promise of a separation of molybdenum from such elements as tungsten or iron.

\section{LOSSES THAT MAY CAUSE ERRORS IN ANALYTICAL PROCEDURES}

An inspection of table 1 is sufficient to show that many elements may be lost entirely or in part in evaporations with sulfuric or perchloric acid in many of the usual analytical operations. The losses indicated for gold, bismuth, molybdenum, phosphorus, tellurium, vanadium, and thallium are small, but may cause serious error if the material being analyzed contains high percentages, as for example, gold in dental gold alloys. On the other hand, with the usual small amounts of vanadium in steels, the loss in distillations with perchloric and hydrochloric acids is seldom of any consequence.

Loss of chromium during its oxidation with perchloric acid likewise is of importance. If hydrochloric acid is present during the oxidation, chromyl chloride may be formed and volatilized. A slight loss of chromium may occur even if no hydrochloric acid is added before or during the oxidation with perchloric acid, because hydrochloric acid is probably one of the products of the reaction when trivalent chromium is oxidized by perchloric acid. In five experiments in which $0.1 \mathrm{~g}$ of chromium as the sulfate was oxidized with perchloric acid and heated for 5 minutes at $200^{\circ}$ to $220^{\circ} \mathrm{C}$ in the apparatus illustrated in figure 1 , from 0.2 to $0.4 \mathrm{mg}$ of chromium was found in the distillates. This probably is the chief cause for the slightly low results

\footnotetext{
- See also A. A. Noyes and W. C. Bray, A System of Qualitative Analysis for the Rare Elements, p. 37 and 292 (The Macmillan Co., New York, N. Y., 1927).

${ }^{7}$ For the distillation of rhenium from phosphoric acid solution, see W. Geilman und F. Weibke, Z. anorg. allgem. Chem. 199, 126 (1931).
} 
obtained in the determination of chromium by oxidation with perchloric acid. ${ }^{8}$ Of interest is the action of phosphoric acid in preventing volatilization of vanadium, molybdenum, tin, and bismuth in the hydrochloric-phosphoric-perchloric acid series (procedure 3), or of vanadium and molybdenum in the hydrobromic-phosphoric-perchloric acid series (procedure 4).

Washington, February 17, 1939.

G. E. F. Lundell, J. I. Hoffman, and H. A. Bright, Chomical Analysis of Iron and Steel, p. 298 (J. Wiley \& Sons, Now York, N. Y., 1931 ed.), and Chemists U. S. Steel Corporation, Sampling and Analysis of Car. bon and Alloy Steels, p. 70 (Reinhold Publishing Co., New York, N. Y., 1938 ed.). 